\title{
Health literacy among participants from neighbourhoods with different socio- economic statuses in the southern region of Hungary: a pilot study
}

\author{
Henrietta Bánfai-Csonka ${ }^{1,2^{*}}$ (D) Bálint Bánfai ${ }^{2}$ (D) Sára Jeges ${ }^{2}$, Brigitta Gyebnár ${ }^{3}$ and József Betlehem² (D)
}

\begin{abstract}
Background: Health literacy $(\mathrm{HL})$ has a deep impact on people's decisions about their health and health care system. Measurement and improvement of HL level is essential to develop an appropriate health care system. The aim of the study was to (1) conduct a pilot study among the population of Baranya County in Hungary with different socio-economic statuses, (2) evaluate the HL level and (3) found the correlations between socio-economic data, emergency departments' visits, medical history and HL.

Methods: In a cross-sectional study conducted in 2019 with 186 participants, socio-economic status, health status, $\mathrm{HL}$ level and knowledge about the triage system were measured. The questionnaire included questions on socioeconomic status, previous chronic diseases, and satisfaction with the emergency care system as well as the standardised European Health Literacy Survey Questionnaire (HLS-EU-Q47). Descriptive statistical analysis (mean, SD, mode) and mathematical statistical analysis (ANOVA, chi ${ }^{2}$ test, Pearson Correlations, Two sample t-test) were applied. SPSS 24.0 statistical software was used to analyse the data. Relationships were considered significant at the $p<0.05$ level.

Results: One hundred and eighty-six people were involved in the research, but 45 of them were excluded ( $N=$ 141). The participation rate was $75.8 \%$. There were significant differences in HL levels by gender and educational level $(p=0.017)$, health education $(p=0.032)$ and presence of children in the household $(p=0.049)$. Educational level $(p=0.002)$ and type of settlement $(p=0.01)$ had strong impacts on economic status. We found that $46.1 \%$ of the participants had limited comprehensive $\mathrm{HL}(\mathrm{CHL})$ level. This proportion was slightly lower for the disease prevention sub-index (33.3\%). The average $\mathrm{CHL}$ index score was $34.8 \pm 8.7$ points, the average health care sub-index score was $34.6 \pm 9.7$ points, the average disease prevention sub-index score was $35.8 \pm 9.9$ points, and the average health promotion sub-index score was $34.2 \pm 9.4$ points. $46.1 \%$ of the examined population in Hungary had limited HL level.

\footnotetext{
* Correspondence: henrietta.csonka@etk.pte.hu; csonka.henrietta@pte.hu

${ }^{1}$ Faculty of Health Sciences, Doctoral School of Health Sciences, University of Pécs, Pécs Vörösmarty st. 4, Pécs 7622, Hungary

${ }^{2}$ Faculty of Health Sciences, Institute of Emergency Care and Pedagogy of Health, University of Pécs, Pécs Vörösmarty st. 4, Pécs 7622, Hungary

Full list of author information is available at the end of the article
}

(c) The Author(s). 2020 Open Access This article is licensed under a Creative Commons Attribution 4.0 International License, which permits use, sharing, adaptation, distribution and reproduction in any medium or format, as long as you give appropriate credit to the original author(s) and the source, provide a link to the Creative Commons licence, and indicate if changes were made. The images or other third party material in this article are included in the article's Creative Commons licence, unless indicated otherwise in a credit line to the material. If material is not included in the article's Creative Commons licence and your intended use is not permitted by statutory regulation or exceeds the permitted use, you will need to obtain permission directly from the copyright holder. To view a copy of this licence, visit http://creativecommons.org/licenses/by/4.0/ The Creative Commons Public Domain Dedication waiver (http://creativecommons.org/publicdomain/zero/1.0/) applies to the data made available in this article, unless otherwise stated in a credit line to the data. 
(Continued from previous page)

Conclusions: Socio-economic status has a strong influence on HL level. It is not enough to improve awareness but we need to improve knowledge and cooperation with the doctors and health care system.

Keywords: Health literacy, Emergency care, Health literacy sub-index, Low-income populations

\section{Background}

Decisions made by patients have profound impacts on the health care system, diagnostic and therapeutic decisions, and the disease prevention procedures [1].

Health literacy (HL) is the skill of accessing, understanding and using health information and making decisions about one's health and health care [1]. A patient with an adequate HL level has the appropriate information to make adequate decisions about his/her own health, their dependents' health and community health [2]. There are many instruments to measure HL level, the most common of which are the Short Test of Functional Health Literacy (S-TOFHLA), Test of Functional Health Literacy (TOFHLA) [3], Health Literacy Questionnaire (HLQ), Newest Vital Sign (NVS) and Rapid Estimate of Adult Literacy in Medicine Health Literacy Test (REALM) [3]. In Europe, the European Health Literacy Survey Questionnaire (HLS-EU-Q47) was used for a continental survey that included 8 European countries [4].

The incidence of limited HL level is more common than expected. In Europe, 1 in 10 people has insufficient HL level, and one in two has limited HL level [4]. In Portugal, almost three of four people [5] has limited HL level, and every second person in Hungary has limited HL level [6]. Low HL level can cause a higher number of return emergency department (ED) visits [7] and higher mortality (12.8\%) due to cardiovascular disease (CVD) in a year of hospitalisation [8]; however, with adequate education, these risks can be reduced [9]. For people with more chronic diseases $[10,11]$ and for the ageing population $[10,12,13]$, it is more difficult to find and understand information. Inadequate and marginal HL level is associated with socioeconomic and self-related health status. People living in rural environment $(O R=2.25)$ and having poor income $(O R=1.59)$ were significantly correlated with low HL level which cause more frequent hospital treatments and family doctors' visits [13]. Low HL level are more frequent in low-income populations $[14,15]$. However, some studies have shown no correlations between age [11], socioeconomic status [11] and HL. Low HL can also be associated with an unhealthy lifestyle, physical inactivity [16, 17], an unhealthy diet [17], smoking [17] and obesity $[16,17]$. For patients with CVD, their HL level are associated with their health behaviours and health status [18].
HL can be identified as a key point in public health [19], but the public and government have been involved in only some recent research on this topic [20]. Schools may be the best place to start to develop HL [21], but adults can also be involved in HL programmes [22].

Why is it difficult to make the correct decisions about our health? First, in the age of the internet and social media, we cannot stop or control the misleading information. There are many forums with fake news that can provide inadequate information to the public [23]. If health care managers would like people to use the correct websites with correct information, they should make these sites modern and user friendly with simple designs [24]. Public awareness and HL can also be increased with the help of social media related to CVD and emergency cases [25]. HL also affects patient-physician communication [3]. This gap can be the reason why physicians and patients think in different ways [26]. Hospital materials are also written in complex form; for better communication, these materials need to be improved [3]. Patients need more attention and compassion from providers [27].

To the best of our knowledge, a previous study in Hungary that compared HL level based on medical and socio-economic status, especially in populations with low socio-economic status has not been conducted so far. Therefore, the aim of this pilot study was to investigate the HL level among low-income populations in the southern part of Hungary in Barany County. We wanted to measure the indicators of health literacy along which we can create a "health literacy program". We measured HL level and the level of knowledge about triage system and the success with EDs. We also assessed participants' vital parameters and medical histories regarding previous chronic diseases. We were looking for relationships between HL level and socio-economic data, medication habits and knowledge.

\section{Methods}

A cross sectional study was conducted to investigate the HL level among people with low socio-economic status and to found correlations between visiting and satisfaction with ED units, knowledge about the triage system and patients' medical habits. 


\section{Study population}

Participants were recruited by the Health Development Office in Sellye between April and May 2019. For convenience sampling the respondents were from two villages and one town in Baranya county. One hundred and eighty-six people were involved in the study. All of them were above 18 years. Those who suffered from mental health disease, who are in social care or who did not fit the whole questionnaire were excluded. All participants received an informative document about the survey protocol and data collection, including about the collection of anamnestic data, vital parameters, knowledge about the health care system, especially knowledge about emergency care and HL level.

\section{Data collection}

Data collection was conducted with the following test battery, consists of two main parts. At the beginning the socio-economic part consisted of questions on age, gender, educational level, health educational level, settlement status, marital status, and household income. Regarding the participants' health conditions, we measured their blood pressure, pulse, oxygen saturation, body weight, and body height and asked questions to record medical history and collect information on their chronic diseases and medication habits. The normal BMI value was considered between 18.5 and 24.99 [28]. In reference to knowledge levels, there were some questions about the triage system.

A Likert scale was used to measure satisfaction with the emergency care system, workers and information system. Visits to family doctors on duty were excluded from this part of the research.

At the second part of the questionnaire the HLS-EUQ47 questionnaire was used to assess HL level. The HLS-EU-Q47 has 4 indices, i.e., the comprehensive HL index (cHL) and 3 specific dimension sub-indices: the health care $(\mathrm{HC})$, disease prevention (DP) and health promotion (HP) sub-indices. Four categories are used to characterise respondents' HL level: inadequate, problematic, sufficient and excellent [2, 4]. This questionnaire was previously validated in Hungary [6] and showed good internal reliability (Cronbach's alpha for the cHL index: 0.97; Cronbach's alpha for the HC sub-index: 0.92; Cronbach's alpha for the DP sub-index: 0.92; and Cronbach's alpha for the HP sub-index: 0.93) [6].

First, the validity of the sub-indexes was tested because the answers of each participant could be considered only if the participant provided fewer than 4 "I don't know" answers. Only 1 "I don't know" answer was allowed for questions 1-16 (HC sub-index) and for questions 17-31 (DP sub-index), and 2 "I don't know" answers were allowed for questions 32-47 (HP sub-index). Thirty-four percent of the participants had one "I don't know" answer for the HC sub-index, $22.7 \%$ had one "I don't know" answer for the DP sub-index, and 34.8\% had one "I don't know" answer for the HP sub-index.

The coherence between the questions in the cHL index and sub-indexes was high, and the Cronbach's alpha values were as follows: cHL index: 0.976, HC: 0.933, DP: 0.937 and HP: 0.919.

Second, the cHL index and sub-index descriptive values were measured. The participants' HL level between 0 and 25 points were considered inadequate, between 26 and 33 points were considered problematic, between 34 and 42 points were considered sufficient and between 43 and 50 points were considered excellent. Participants in the inadequate and problematic groups were considered to have limited HL level. The statistical analysis of this part of the survey was performed as described in previous studies $[2,6]$.

All participants had to complete the questionnaire with an interviewer, who was a heath care worker and knew the rules for completing the questionnaire. The interviewer were in a separated room with the participants, they could not hear each other during the answering process. First the anthropometric dates were measured, after that they answered the questions.

\section{Statistical analysis}

Descriptive statistical analysis (mean, SD, percentage, mode) was used to describe the sample. Mathematical statistical analysis (ANOVA, chi $^{2}$ test, Pearson correlations, Two sample t-test) was used to determine the relationships between the nominal variables (e.g., gender, educational level) and continuous variables (e.g., HL level). One-way ANOVA and t-test was applied to test the association between HL level, knowledge (knowledge about the triage system), satisfaction with the ED visits and demographic characteristics (gender, education level, type of settlement, health education economic status, marital status, health education, children are household). Pearson correlation was applied to test HL level (e.g. HL level vs. age). SPSS 24.0 statistical software was used to analyse the data. Relationships were considered significant at the $p<0.05$ level.

\section{Results \\ Socio-economic results}

One hundred and eighty-six people were involved in the research, but 45 of them were excluded $(N=141)$ because they did not have time to complete the whole questionnaire or they did not want to answer the sociodemographic questions. The participation rate was $75.8 \%$. The description of socio-economic data can be found in Table 1.

There were significant differences in HL level and educational level $(p=0.017)$, health education $(p=$ 
Table 1 Description of the socio-economic data

\begin{tabular}{|c|c|c|c|}
\hline Characteristics & Male & Female & Sample \\
\hline & $41(29.1 \%)$ & $100(70.9 \%)$ & $141(100 \%)$ \\
\hline Age (year) & $46.8 \pm 16.52$ & $45.59 \pm 12.75$ & $45.94 \pm 13.9$ \\
\hline \multicolumn{4}{|l|}{ Educational level } \\
\hline Less than primary school & 0 & $1(1 \%)$ & $1(0.7 \%)$ \\
\hline Primary school & $10(24.4 \%)$ & $31(31 \%)$ & $41(21.9 \%)$ \\
\hline Vocational school (did not graduate) & $10(24.4 \%)$ & $4(4 \%)$ & $14(9.9 \%)$ \\
\hline Vocational school (graduated) & $6(14.6 \%)$ & $24(24 \%)$ & $30(21.3 \%)$ \\
\hline Grammar school & $6(14.6 \%)$ & $12(12 \%)$ & $18(12.8 \%)$ \\
\hline University at the BSc level & $5(12.2 \%)$ & $20(20 \%)$ & $25(17.7 \%)$ \\
\hline University at the MSc level & $4(9.8 \%)$ & $8(8 \%)$ & $12(8.5 \%)$ \\
\hline \multicolumn{4}{|l|}{ Health education } \\
\hline Yes & $4(9.8 \%)$ & $26(26 \%)$ & $30(21.3 \%)$ \\
\hline No & 37 (90.2\%) & $74(74 \%)$ & $111(78.7 \%)$ \\
\hline \multicolumn{4}{|l|}{ Type of settlement } \\
\hline Village & $16(39 \%)$ & $53(53 \%)$ & 69 (49\%) \\
\hline Town & $18(43.9 \%)$ & $29(29 \%)$ & $47(33.3 \%)$ \\
\hline City & $7(17.1 \%)$ & $18(18 \%)$ & $25(17.7 \%)$ \\
\hline \multicolumn{4}{|l|}{ Economic status (average) } \\
\hline Below average & $18(43.9 \%)$ & 47 (47\%) & 65 (46.1\%) \\
\hline Average & $17(41.5 \%)$ & $47(47 \%)$ & $64(45.4 \%)$ \\
\hline Above average & $6(14.6 \%)$ & $6(6 \%)$ & $12(8.5 \%)$ \\
\hline \multicolumn{4}{|l|}{ Marital status } \\
\hline Single & $10(24.4 \%)$ & $25(25 \%)$ & $35(24.8 \%)$ \\
\hline Married & $18(43.9 \%)$ & $38(38 \%)$ & $56(39.7 \%)$ \\
\hline Living with a partner & $11(26.8 \%)$ & $23(23 \%)$ & $34(24.1 \%)$ \\
\hline Divorced & $1(2.4 \%)$ & $10(10 \%)$ & $11(7.8 \%)$ \\
\hline Widowed & $1(2.4 \%)$ & $4(4 \%)$ & $5(3.5 \%)$ \\
\hline \multicolumn{4}{|l|}{ Child/children in household } \\
\hline Yes & $10(24.4 \%)$ & $42(42 \%)$ & 52 (36.9\%) \\
\hline No & 31 (75.6\%) & $58(58 \%)$ & 89 (63.1\%) \\
\hline
\end{tabular}

$0.032)$ and presence of children in the household ( $p=$ $0.049)$. Educational level $(p=0.002)$ and type of settlement $(p=0.01)$ had strong impacts on economic status.

\section{Results from the anamnestic data and vital parameters}

The mean body mass index (BMI) of the participants was 26.23 , which means that the pilot study population was overweight. A total of $35.4 \%$ of the participants had a normal BMI. The mean blood pressure was $125 / 80$ $\mathrm{mmHg}$, which is normal according to the Hungarian Society of Hypertension [29], but some participants had higher values. Those who suffered from hypertension did not take their medications regularly. The oxygen saturation of respondents was in the normal range, but in one case, it was lower $\left(\mathrm{SpO}_{2}: 88 \%\right)$ but hat participant suffered from chronic obstructive respiratory disease (COPD). Less than half of the participants (46.1\%) had to take medications regularly because they had chronic diseases, and 14 (9.9\%) had diseases but did not take medications. The prevalence of previous chronic diseases can be found in Table 2. Twenty-four participants (27.6\%) did not take their prescribed medications.

\section{Results regarding emergency department visits and knowledge about the triage system}

Sixty-nine (48.9\%) of the participants had ED visits during the past year. Most of the patients were taken to the ED by the National Ambulance Service with a referral $(21.7 \%)$ or without a referral $(18.8 \%)$ from their family 
Table 2 Prevalence of chronic diseases $(n=65)$

\begin{tabular}{lll}
\hline & Yes & No \\
\hline Hypertension & $33(50.8 \%)$ & $32(49.2 \%)$ \\
Diabetes mellitus & $7(10.8 \%)$ & $58(89.2 \%)$ \\
Cardiac disease & $10(15.4 \%)$ & $55(84.6 \%)$ \\
Arthritis & $3(4.6 \%)$ & $62(95.4 \%)$ \\
Pulmonary disease & $6(9.2 \%)$ & $59(90.8 \%)$ \\
Psychiatric disease & $4(6.2 \%)$ & $61(93.8 \%)$ \\
Other & $18(27.7 \%)$ & $47(72.3 \%)$ \\
\hline
\end{tabular}

doctor (GP). A total of $92.8 \%$ of patients thought that it was necessary to go to the ED, but the number of admissions to other hospital wards was low (28.29\%). At the end of their ED stays, $92.4 \%$ read the outpatient paper, and $27.3 \%$ did not inform their GPs about the results of their ED visits.

Regarding the question "Do you know what triage means?", 65.2\% of the participants answered "Yes", but when they had to select an answer to indicate the definition of triage, only $46.8 \%$ of them chose to the correct answer. A total of $86.5 \%$ of participants wanted to have more information about the Hungarian health care and emergency health care system. The desired means of receiving information included personal interaction (41.3\%), the internet (52.1\%), television (33.1\%), brochures $(22.3 \%)$, the radio or other applications (13.2\%) and other forums (e.g., school) (8.3\%). There was no significant difference in knowledge about the triage system based on the number of ED admissions $(p=0.292)$.
A total of $46.4 \%$ of the patients were triaged within 10 min, but $27.5 \%$ were triaged only after $30 \mathrm{~min} ; 47.1 \%$ of the patients had to wait less than $15 \mathrm{~min}$, and only $10.3 \%$ had to wait more than $2 \mathrm{~h}$. In total, $61.2 \%$ of the patients had to stay in EDs 1 to $6 \mathrm{~h}$, but $59.7 \%$ of them did not know the reason for waiting.

The results of the satisfaction with the ED admission, care, workers and information giving system can be seen in Table 3.

In the examination of differences of satisfaction levels by education level, there were significant differences only for the cleanliness of the rooms $(p=0.046)$, and in the examination by gender, there was a significant difference in the cleanliness of the rooms $(p=0.002)$ as well.

\section{Health literacy results}

The average cHL index score was $34.8 \pm 8.7$ points, the average $\mathrm{HC}$ sub-index score was $34.6 \pm 9.7$ points, the average DP sub-index score was $35.8 \pm 9.9$ points, and the average HP sub-index score was 34.2 points \pm 9.4 points. The HL level categories in the different indexes can be seen in Table 4 .

According to Table 4, 46.1\% of the examined population in Hungary had limited HL level; 48.2, 33.3 and $49.6 \%$ of the participants had limited HL levels as measured by the HC, DP, and HP sub-indexes, respectively. This finding indicates that close to half of the participants had limited HL levels, except for on the DP sub-index.

Table 5 shows the relationship between HL indices and the socio-economic characteristics of the sample.

Table 3 Satisfaction with ED visits $(n=69)$

\begin{tabular}{|c|c|c|c|c|c|c|c|}
\hline & $\begin{array}{l}1 \\
\text { Not at all } \\
\text { satisfied }\end{array}$ & $\begin{array}{l}2 \\
\text { Not } \\
\text { satisfied }\end{array}$ & $\begin{array}{l}3 \\
\text { Neither satisfied nor } \\
\text { dissatisfied }\end{array}$ & $\begin{array}{l}4 \\
\text { Satisfied }\end{array}$ & $\begin{array}{l}5 \\
\text { Very } \\
\text { satisfied }\end{array}$ & $\begin{array}{l}6 \\
\text { Have not } \\
\text { answered }\end{array}$ & $\begin{array}{l}\text { Mean } \\
\text { points }\end{array}$ \\
\hline Administrators' work & $9(13 \%)$ & $7(10.1 \%)$ & $8(11.6 \%)$ & $\begin{array}{l}24 \\
(34.8 \%)\end{array}$ & $21(30.4 \%)$ & - & 3.59 \\
\hline Paramedics' and nurses' work & $2(2.9 \%)$ & $6(8.8 \%)$ & $10(14.7 \%)$ & $\begin{array}{l}21 \\
(30.9 \%)\end{array}$ & $29(42.6 \%)$ & - & 3.97 \\
\hline Doctors' work & $3(4.3 \%)$ & $5(7.2 \%)$ & $14(20.3 \%)$ & $\begin{array}{l}18 \\
(26.1 \%)\end{array}$ & $29(42 \%)$ & - & 3.94 \\
\hline Medical orderlies' work & $5(7.2 \%)$ & $3(4.3 \%)$ & $13(18.8 \%)$ & $\begin{array}{l}22 \\
(31.9 \%)\end{array}$ & $23(33.3 \%)$ & $3(4.3 \%)$ & 3.67 \\
\hline Radiographers' work & $2(2.9 \%)$ & $5(7.2 \%)$ & $5(7.2 \%)$ & $\begin{array}{l}21 \\
(30.4 \%)\end{array}$ & $25(36.2 \%)$ & $11(15.9 \%)$ & 3.42 \\
\hline Information given about results & $8(11.6 \%)$ & $3(4.3 \%)$ & $14(20.3 \%)$ & $20(29 \%)$ & $24(34.8 \%)$ & - & 3.71 \\
\hline Information given about current status & $9(13 \%)$ & $4(5.8 \%)$ & $13(18.8 \%)$ & $\begin{array}{l}24 \\
(34.8 \%)\end{array}$ & $19(27.5 \%)$ & - & 3.58 \\
\hline $\begin{array}{l}\text { Information given about the care } \\
\text { process }\end{array}$ & $9(13 \%)$ & $9(13 \%)$ & $17(24.6 \%)$ & $\begin{array}{l}17 \\
(24.6 \%)\end{array}$ & $17(24.6 \%)$ & - & 3.35 \\
\hline $\begin{array}{l}\text { Information given about the whole } \\
\text { procedure }\end{array}$ & $14(20.3 \%)$ & $4(5.8 \%)$ & $12(17.4 \%)$ & $\begin{array}{l}21 \\
(30.4 \%)\end{array}$ & $18(26.1 \%)$ & - & 3.36 \\
\hline Cleanliness of the rooms & 7 (10.1\%) & $6(8.7 \%)$ & $13(18.8 \%)$ & $20(29 \%)$ & $23(33 \%)$ & - & 3.67 \\
\hline
\end{tabular}


Table $4 \mathrm{HL}$ levels in the different indexes

\begin{tabular}{lllll}
\hline & Inadequate & Problematic & Sufficient & Excellent \\
\hline $\mathrm{CHL}$ & $16.3 \%(23)$ & $29.8 \%(42)$ & $32.6 \%(46)$ & $21.3 \%(30)$ \\
$\mathrm{HC}$ & $15.6 \%(22)$ & $32.6 \%(46)$ & $27.7 \%(39)$ & $24.1 \%(34)$ \\
$\mathrm{DP}$ & $14.9 \%(21)$ & $18.4 \%(26)$ & $40.5 \%(57)$ & $26.2 \%(37)$ \\
$\mathrm{HP}$ & $19.9 \%(28)$ & $29.7 \%(42)$ & $29.1 \%(41)$ & $21.3 \%(30)$ \\
\hline
\end{tabular}

Table 5 Relationships (level of significance) between the HL index scores, sub-index scores and socio-demographic characteristics (binary analysis)

\begin{tabular}{|c|c|c|c|c|c|}
\hline & & $\mathrm{CHL}$ & $\mathrm{HC}$ & DP & $\mathrm{HP}$ \\
\hline \multirow[t]{2}{*}{ Age (years) } & $p$ & 0.549 & 0.978 & 0.490 & 0.350 \\
\hline & $r^{a}$ & -0.051 & -0.002 & $-0,058$ & -0.080 \\
\hline Gender & $p^{b}$ & 0.393 & $0.031^{*}$ & 0.499 & 0.738 \\
\hline Female & mean & 34.6 & 33.8 & 35.5 & 34.5 \\
\hline Male & mean & 36.0 & 37.3 & 36.8 & 33.9 \\
\hline Educational level & $p^{c}$ & $0.018^{*}$ & 0.253 & $<0.001^{*}$ & 0.107 \\
\hline primary school & mean & 31.2 & 31.8 & 30.4 & 31.5 \\
\hline secondary school & mean & 36.7 & 36.5 & 38.1 & 35.5 \\
\hline university degree & mean & 36.4 & 35.2 & 38.3 & 35.7 \\
\hline Health education & $p^{b}$ & $<0.001^{*}$ & $<0.001^{*}$ & $<0.001^{*}$ & $<0.001^{*}$ \\
\hline yes & mean & 39.9 & 39.5 & 41.7 & 38.5 \\
\hline no & mean & 33.7 & 33.5 & 34.3 & 33.2 \\
\hline Type of settlement & $p^{c}$ & $0.043^{*}$ & 0.350 & $0.003^{*}$ & 0.111 \\
\hline village & mean & 33.4 & 33.4 & 33.5 & 33.1 \\
\hline town & mean & 35.3 & 35.5 & 35.9 & 34.5 \\
\hline county town & mean & 38.3 & 36.3 & 41.4 & 37.2 \\
\hline Economic status & $p^{c}$ & $0.027^{*}$ & $0.025^{*}$ & 0.117 & $0.022^{*}$ \\
\hline below average & mean & 33.1 & 32.4 & 34.4 & 32.5 \\
\hline average & mean & 36.1 & 36.7 & 36.6 & 35.2 \\
\hline above average & mean & 39.3 & 37.5 & 40.4 & 40.1 \\
\hline Marital status & $p^{c}$ & 0.864 & 0.891 & 0.708 & 0.920 \\
\hline single & mean & 34.0 & 33.8 & 34.8 & 33.5 \\
\hline married & mean & 35.9 & 35.8 & 37.4 & 34.5 \\
\hline living in relationship & mean & 35.2 & 35.0 & 35.4 & 35.3 \\
\hline divorced & mean & 33.8 & 33.6 & 34.4 & 33.5 \\
\hline widow & mean & 34.8 & 34.6 & 34.1 & 35.9 \\
\hline Children in household & $p^{b}$ & $0.015^{*}$ & 0.391 & $0.009^{*}$ & $0.001^{*}$ \\
\hline yes & mean & 37.3 & 35.6 & 38.6 & 37.7 \\
\hline no & mean & 33.6 & 34.2 & 34.3 & 32.4 \\
\hline
\end{tabular}

There was no significant difference in cHL level by gender $(p=0.393)$. There were significant difference in cHL level by health education $(p=0.001)$, presence of children in the household $(p=0.029)$, educational level $(p=0.02)$, and type of settlement $(p=0.36)$. People living in towns had higher cHL level than those living in villages and cities. Economic status also had a strong impact on cHL level $(p=0.035)$. Examining the relationship between HL level and educational level according to the Scheffe Post Hock Test there was significant difference between the low educational level (primary school) and the high educational level (university degree). According to the residency relationship was found between villagers and those who are living in county towns. People with below-average income regularly had lower HL level than those with above-average income.

Satisfaction and HL level were not correlated significantly $(p>0.05)$; only satisfaction with radiographers showed a significant difference by HL level $(p=0.038)$.

There were also significant differences in cHL level between those who had chronic diseases and were taking medication $(p=0.021)$ or not taking medication $(p=$ 0.007).

\section{Discussion}

In this study we measured the HL level among Hungarians from regions with low socio-economic status.

The main achievement of the study was the summary of data from one questionnaire/survey of the demographics, economic and health statuses, knowledge of triage system and satisfaction with the EDs and HL level.

We found that $46.1 \%$ of the participants had limited cHL level. This percentage is similar to that of the general Hungarian population [6]. The percentage of participants with limited HL level was slightly lower for the DP sub-index (33.3\%). This finding suggests that the study population can understand and act effectively regarding this aspect of health care. They understand the importance of health screenings and know when it is necessary to receive this kind of examination.

One international study [11] found no significant difference in HL level by demographic characteristics. In our research, we found that educational level, health education, type of settlement, children in the household and economic status had strong effects on cHL level. Differences by gender were observed only for the HC and HP sub-indexes, and differences by age were observed only in the DP sub-index. The difference in $\mathrm{cHL}$ level by BMI was not significant, but HL increased as BMI decreased. Therefore, obesity can also influence cHL level $[16,17]$.

Accessing information about health and health care systems via social media is very popular, but the information that social media offer can be unsafe and false 
[23]. Regardless, most of the participants wanted to obtain information about the health care system and ED via the internet and television. In addition, personal contact is necessary. Schools and outpatient materials can also be good ways to communicate information to the public and patients and to develop HL [21, 22].

\section{Limitations of the study}

We recruited participants from the remaining villages (characterised with low income and isolation) in the region where we intended to collect our data, but we conducted the research in collaboration with the Health Development Office in Sellye, collecting data via their social programmes ("Health Day" and "Parents' club"). Therefore, we could not exclude people who lived in other settlements in the region or had better social and economic statuses.

We conducted assessments in only one part of Hungary that was selected by the research group, so we cannot ensure that the sample was representative of this region. The modest sample size may also affect the uncertainty of the results.

Data about health and medical histories were selfreported, and we could not determine their reliability. The whole questionnaire was based on self-reported data, so we need to conduct a quantitative part of the study to verify the HL level.

Despite these limitations of the study, we think that the study provides a good basis for a nationwide research.

\section{Conclusions}

The circumstances of the respondents can have an effect on HL level. If we would like to improve HL level in our country, we need to concentrate on regions with low average income as well. It is not enough to improve awareness but we need to improve knowledge and cooperation with the doctors and health care system.

\begin{abstract}
Abbreviations
BMI: Body mass index; CHL: Comprehensive health literacy; COPD: Chronic obstructive respiratory disease; CVD: Cardiovascular disease; DP: Disease prevention; ED: Emergency department; GP: General practitioner (family doctor); HC: Health care; HL: Health literacy; HLQ: Health Literacy Questionnaire; HLS-EU-Q47: European Health Literacy Survey Questionnaire; HP: Health promotion; NVS: Newest Vital Sign; REALM: Rapid Estimate of Adult Literacy in Medicine Health Literacy Test; SD: Standard deviation; SPSS: Statistical package for the Social Sciences; S-TOFHLA: Short Test of Functional Health Literacy; TOFHLA: Test of Functional Health Literacy
\end{abstract}

\section{Acknowledgements}

The authors acknowledge to Dr. Ildikó Barta for her help in providing space for data collectionng.

\section{About this supplement}

This article has been published as part of BMC Public Health Volume 20 Supplement 1, 2020: Level and Determinants of Physical Activity in the V4 Countries - Part 1. The full contents of the supplementare available online at
URL.https://bmcpublichealth.biomedcentral.com/articles/supplements/ volume-20-supplement-1.

\section{Authors' contributions}

All authors read and approved the final manuscript. JB conceived, designed and managed the study, BB, HBCs and BGy contributed to the study conceptualization and provided critical editorial input to the interpretation of the data and contributed to the data collection and analysis, JS contributed in analysis of data.

\section{Funding}

Publication costs were funded by the GINOP 2.3.2-15-2016-00047 grant. The current work was partially supported by the ÚNKP-19-3-I New National Excellence Program of the Ministry for Innovation and Technology.

\section{Availability of data and materials}

The dataset supporting the conclusions of this article and the questionnaire is available from the corresponding author on reasonable request.

\section{Ethics approval and consent to participate}

The Hungarian Scientific and Research Ethics Committee permitted the research. The authorisation number is 20018-2-/2019/EKU.

All participants received detailed information about the research and signed the declaration of consent if they agreed with the research conditions and wanted to participate. The investigation conforms to the principles outlined in the Declaration of Helsinki.

\section{Consent for publication}

Not applicable.

\section{Competing interests}

The authors declare that they have no competing interests.

\section{Author details}

${ }^{1}$ Faculty of Health Sciences, Doctoral School of Health Sciences, University of Pécs, Pécs Vörösmarty st. 4, Pécs 7622, Hungary. ${ }^{2}$ Faculty of Health Sciences, Institute of Emergency Care and Pedagogy of Health, University of Pécs, Pécs Vörösmarty st. 4, Pécs 7622, Hungary. ${ }^{3}$ Department of Children Affairs, Women's Policy and Equal Opportunities, Ministry of State for Family and Youth Affairs, Ministry of Human Capacities, Szalay st.10-14, Budapest 1055, Hungary.

Received: 18 May 2020 Accepted: 19 May 2020

Published: 17 August 2020

\section{References}

1. Sorensen K, Van den Broucke S, Fullam J, Doyle G, Pelikan J, Slonska Z, et al. Health literacy and public health: a systematic review and integration of definitions and models. BMC Public Health. 2012;12:80.

2. Jessup RL, Osborne RH, Beauchamp A, Bourne A, Buchbinder R. Health literacy of recently hospitalised patients: a cross-sectional survey using the health literacy questionnaire (HLQ). BMC Health Serv Res. 2017;17:52.

3. Griffey RT, Kennedy SK, McGowan L, Goodman M, Kaphingst KA. Is low health literacy associated with increased emergency department utilization and recidivism? Acad Emerg Med. 2014;21:1109-15.

4. Mayberry LS, Schildcrout JS, Wallston KA, Goggins K, Mixon AS, Rothman RL, et al. Health literacy and 1-year mortality: mechanisms of association in adults hospitalized for cardiovascular disease. Mayo Clin Proc. 2018;93:1728-38.

5. Lustigova M, Dzurova D, Pikhart H, Kubinova R, Bobak M. Cardiovascular health among the Czech population at the beginning of the 21 st century: a 12-year follow-up study. J Epidemiol Community Health. 2018;72:442-8.

6. Koltai JA, Kun E. Hungarian health literacy in international comparison. Egészségfejlesztés. 2016;62:3-20.

7. Paiva D, Silva S, Severo M, Moura-Ferreira P, Lunet N, Azevedo A. Limited health literacy in Portugal assessed with the newest vital sign. Acta Medica Port. 2017:30:861-9.

8. Sorensen K, Pelikan JM, Rothlin F, Ganahl K, Slonska Z, Doyle G, et al. Health literacy in Europe: comparative results of the European health literacy survey (HLS-EU). Eur J Pub Health. 2015;25:1053-8. 
9. Jessup RL, Osborne RH, Beauchamp A, Bourne A, Buchbinder R. Differences in health literacy profiles of patients admitted to a public and a private hospital in Melbourne, Australia. BMC Health Serv Res. 2018;18:134.

10. Mahdizadeh M, Solhi M. Relationship between self-care behaviors and health literacy among elderly women in Iran, 2015. Electron Physician. 2018; 10:6462-9.

11. N'Goran A, Pasquier J, Deruaz-Luyet A, Burnand B, Haller D, Neuner-Jehle S, et al. Factors associated with health literacy in multimorbid patients in primary care: a cross-sectional study in Switzerland. BMJ Open. 2018;8. e018281.

12. Kickbusch I. Health literacy: addressing the health and education divide. Health Promot Int. 2001;16:289-97.

13. Todorovic N, Jovic-Vranes A, Djikanovic B, Pilipovic-Broceta N, Vasiljevic N, Racic M. Health literacy: current status and challenges in the work of family doctors in Bosnia and Herzegovina. Int J Environ Res Public Health. 2019; 16(8):1324.

14. Ylitalo KR, Meyer RU, Lanning BA, During C, Laschober R, Griggs JO. Simple screening tools to identify limited health literacy in a low-income patient population. Medicine. 2018;97(10):e0110.

15. Kutner $M$, Greenberg E, Jin $Y$. The health literacy of America's adults: results from the 2003 National Assesment of Adult literacy National Center for Education Statistics 2006. https://files.eric.ed.gov/fulltext/ED493284.pdf. Acessed 10 Dec 2019.

16. Wilsher SH, Brainard J, Loke Y, Salter C. Patient and public involvement in health literacy interventions: a mapping review. Res Involv Engagem. 2017;3:31.

17. Paakkari L, George S. Ethical underpinnings for the development of health literacy in schools: ethical premises ('why'), orientations ('what') and tone ('how'). BMC Public Health. 2018;18:326.

18. Seidel G, Kaiser B, Lander J, Dierks M-L. The hannover patient university: advanced mini-med school concept and evaluation results. Health Educ J. 2016;76:38-51.

19. Pelican MJ, Röthlin F, Ganahl K. Comparative report on health literacy in eight EU member states. The European health literacy survey HLS-EU. Maastricht: HLS-EU Consortium; 2012.

20. Friis K, Lasgaard M, Rowlands G, Osborne RH, Maindal HT. Health literacy mediates the relationship between educational attainment and health behavior: a Danish population-based study. J Health Commun. 2016;21:54-60.

21. Aaby A, Friis K, Christensen B, Rowlands G, Maindal HT. Health literacy is associated with health behaviour and self-reported health: a large population-based study in individuals with cardiovascular disease. Eur J Prev Cardiol. 2017;24:1880-8.

22. Merchant RM, Asch DA. Protecting the value of medical science in the age of social media and "fake news". JAMA. 2018;320:2415-6.

23. Mahdizadeh J, Valinejadi A, Pooyesh B, Jafari F, Kahouei M. Students' attitudes towards impact of the health department website on their health literacy in Semnan university of medical sciences. Electron Physician. 2018; 10:6164-71.

24. Yonemoto N, Kada A, Yokoyama H, Nonogi H. Public awareness of the need to call emergency medical services following the onset of acute myocardial infarction and associated factors in Japan. J Int Med Res. 2018:46:1747-55.

25. Herndon JB, Chaney M, Carden D. Health literacy and emergency department outcomes: a systematic review. Ann Emerg Med. 2011;57:334-45.

26. Ruud SE, Hjortdahl P, Natvig B. Is it a matter of urgency? A survey of assessments by walk-in patients and doctors of the urgency level of their encounters at a general emergency outpatient clinic in Oslo, Norway. BMC Emerg Med. 2016;16:22.

27. Cubaka VK, Schriver M, Kayitare JB, Cotton P, Maindal HT, Nyirazinyoye L, et al. 'He should feel your pain': patient insights on patient-provider communication in Rwanda. Afr J Prim Health Care Fam Med. 2018:10:e1-11.

28. Nuttall FQ. Body mass index: obesity, BMI, and health: a critical review. Nutr Today. 2015:50:117-28.

29. Hungarian society of hypertension: guideline of hypertension medical care. Hypertonia és Nephrológia. 2018;Suppl 5:1-36

\section{Publisher's Note}

Springer Nature remains neutral with regard to jurisdictional claims in published maps and institutional affiliations.

\section{Ready to submit your research? Choose BMC and benefit from:}

- fast, convenient online submission

- thorough peer review by experienced researchers in your field

- rapid publication on acceptance

- support for research data, including large and complex data types

- gold Open Access which fosters wider collaboration and increased citations

- maximum visibility for your research: over $100 \mathrm{M}$ website views per year

At BMC, research is always in progress.

Learn more biomedcentral.com/submissions 